\title{
Ruimtelijke effecten van twee eeuwen prostitutiebeleid
}

AUTEURS Manuel Aalbers \& Michaël Deinema

FOTOGRAFIE Alejandro Forero Cuervo \& Barry Fricke

Het Amsterdamse stadsbestuur meent met Plan 1012 de negatieve uitwassen van prostitutie te kunnen bestrijden door ramen op de Wallen te sluiten. De geschiedenis leert echter dat overheidsinterventies problemen in de prostitutie eerder ongrijpbaarder maken en verplaatsen.

Hoe er over prostitutie wordt gedacht, heeft invloed op hoe prostitutie een plaats krijgt in de stad en vice versa. Dat geldt zowel vandaag de dag als aan het begin van de twintigste eeuw. Het bordeelverbod van 1911 en de legalisering van 2000 waren de uitkomst van een verandering in de beeldvorming omtrent prostitutie, maar hadden op hun beurt ook invloed op de beeldvorming van prostitutie. Een verbod en legalisering houden beide een officiële erkenning in. Er komt een formele definitie van prostitutie en er is sprake van een poging tot beheersing. Prostitutie lijkt echter bij uitstek te gedijen buiten het formele om. Pogingen tot formalisering leiden daarom tot een tegenreactie- tot informalisering van bepaalde uitingsvormen van prostitutie- en dat heeft weer consequenties voor de ruimtelijke verspreiding. De ruimtelijke effecten van het verbod van 1911 en de legalisering van 2000 onthullen veel over de dynamiek tussen beeldvorming, interventies en de 'plaats' en vorm van prostitutie in de stad. In beide gevallen verminderde de in het oog springende, maar relatief goed controleerbare concentratie van betaalde sekswerkers. Hieruit valt veel te leren over de mogelijke effecten van Plan 1012.

\section{Legalisering zou controle makkelijker maken en onvrij- willige prostitutie aanpakken.}

Prostitutie in de negentiende eeuw

In 1811 voerde de Franse bezettingsmacht het eerste systeem van bordeelregulering en medische visitatie van prostituees in Nederland in om Napoleons soldaten te beschermen tegen geslachtsziekten. Na de Franse tijd verdween de eis tot regulering uit de nationale wetgeving, maar rond 1850 werd regulering weer wijd gepropageerd, ditmaal door medici en rechtgeaarde burgermannen, die zowel de verspreiding van geslachtsziekten als die van ongewenste zwangerschappen en verkrachtingen wilden voorkomen. In beide gevallen was de regulering bedoeld om buitenhuwelijks geslachtsverkeer beheersbaar te maken, te lokaliseren en de maatschappelijke effecten ervan te minimaliseren. Onthouding was volgens de reguleerders voor mannen geen optie. Bestrijding van de geslachtsdrift van ongehuwde mannen was onrealistisch en bovendien ongezond, luidde het devies. De bevrediging ervan werd gezien als een noodzakelijk kwaad dat zowel in sociale als in ruimtelijke zin een speciale plaats toegewezen moest krijgen. Voor de botviering van hun driften dienden ongetrouwde mannen zich te beperken tot prostituees, vrouwen die toch al 'verdorven' waren en voor wie medische visitatie geen verder eerverlies zou betekenen. En de aangewezen plek voor prostitutie was natuurlijk het bordeel, waar ook weer eisen aan kon worden gesteld wat betreft de locatie en mate van zichtbaarheid.

Enkele steden hadden sinds de Franse tijd een eigen vorm van bordeelregulering voortgezet. Amsterdam, Rotterdam en Utrecht gingen daarom gewoon door op eigen leest. Meer dan dertig andere steden zetten halverwege de negentiende eeuw een nieuw reguleringssysteem op. Het officiële prostitutiebeleid leek dus redelijk algemeen aanvaard. Dit bleek een misvatting te zijn. In de decennia na 1850 kwamen zedenpredikers in geweer tegen de 'wettelijke legitimatie van ontucht', feministen tegen de dubbele moraal en het cultiveren van een 'gedoemde klasse vrouwen', en socialisten zagen prostitutie als de ultieme vorm van kapitalistische uitbuiting. Bovendien waren medische visitaties ineffectief omdat de cliënten, waaronder ook veel gehuwde mannen, niet werden gecontroleerd en veel prostituees de gedwongen visitaties ontdoken. De overregulering vormde een pushfactor voor prostituees en hun uitbaters die 'vrije' prostitutie verkozen boven de gereguleerde bordelen.

Wellicht nog belangrijker was een pullfactor die het hele bordeelwezen ondermijnde. Gedurende de laatste decennia van de negentiende 
eeuw steeg de vraag naar exotisme in het aanbod, en naar alternatieven voor bordeelprostitutie. De toenemende aantallen gegoede burgers hadden vaak een voorkeur voor buitenlandse of minderjarige meisjes. Hoewel buitenlandse meisjes vaak met enige moeite wel te verkrijgen en te 'formaliseren' waren voor bordeelhouders, waren minderjarigen alleen in het geheim 'in de aanbieding'. Behalve hun seksuele voorkeuren speelde waarschijnlijk ook de sociale positie van deze groeiende groep klanten de formele bordelen niet in de hand. Deze waren bij uitstek geschikt om anonieme bezoekers van een stad zoals matrozen of soldaten te bedienen, maar minder geschikt voor moeilijk te bewijzen. Hoewel de ongereguleerde prostitutie de publieke ergernis aanzienlijk vergrootte, richtte de daaruit voortkomende woede zich daarom vooral op de bordelen en de regulering. Daar kwam bij dat bordelen, onder druk van de 'vrije' concurrentie, steeds meer teerden op naïeve en kwetsbare meisjes die zij door middel van subtiele en minder subtiele dwangmiddelen probeerden vast te houden. Exploitanten van bordelen konden daardoor gemakkelijk afgeschilderd worden als een soort slavenhouders.

Rond 1900 verbood de ene na de andere stad daarom het bordeelwezen; Amsterdam bijvoorbeeld in 1897. In 1911 kwam er een landelijk

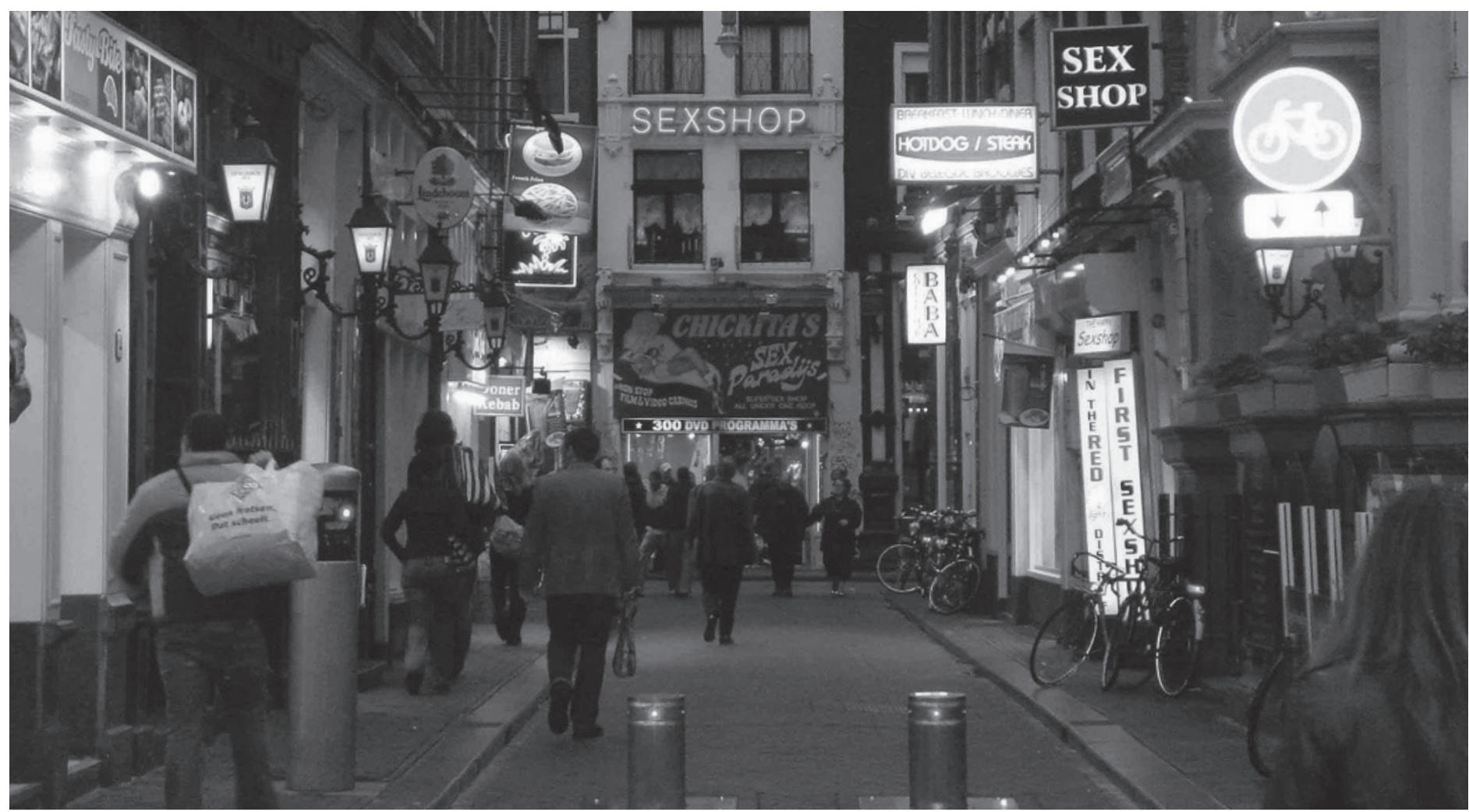

De Wallen in Amsterdam

lokale, vaak gehuwde, statusbewuste lieden voor wie 'ontkenbaarheid' het hoogste goed was. Bordelen echter zorgden voor een dusdanige stigmatisering van specifieke plaatsen dat zij riskant waren voor klanten.

\section{De clandestiene prostitutie bloeide ondanks, of wellicht juist dankzij, de regulering.}

\section{Landelijk bordeelverbod}

De clandestiene prostitutie bloeide ondanks, of wellicht juist dankzij, de regulering. Een groot gebied rondom de Damrak in Amsterdam werd een schemerzone met allerlei soorten seksuele transacties. Hetzelfde gold voor het gebied rond de Zandstraat in Rotterdam. De activiteiten die hier ontplooid werden, kunnen zeker niet als 'onzichtbaar' worden gekwalificeerd. Zij waren duidelijk aanwezig in het straatbeeld, alleen bordeelverbod. De prostitutie verdween hierdoor zeker niet. Sommige voormalige bordelen, zoals het beroemde Maison Weinthal in Amsterdam, werden omgedoopt tot hotel maar bleven nog enkele decennia lang dezelfde diensten aanbieden. Meestal veranderde echter de prostitutievorm en de locatie. Zo vond prostitutie vaak plaats in her en der verspreide sigarenwinkels (die getrouwde mannen een goed alibi gaven) en massagesalons, die hun diensten in codetaal adverteerden in tijdschriften. Prostitutie dook weer onder, was niet meer duidelijk afgebakend en vermengde zich weer met de 'gewone' maatschappij. $\mathrm{Na}$ de Tweede Wereldoorlog zorgde de steeds liberalere sfeer in Amsterdam voor een hergroepering van de prostitutie op de plaatsen waar zij van oudsher geconcentreerd was, zoals de Wallen, de Spuistraat en de Zeedijk.

\section{Legalisering van prostitutie}

In 1999 besloot de Tweede Kamer de bordeelwet van 1911 in te trekken en daarmee werd prostitutie in Nederland per 1 oktober 2000 gelegaliseerd. De afschaffing van de bordeelwet was, net als de 


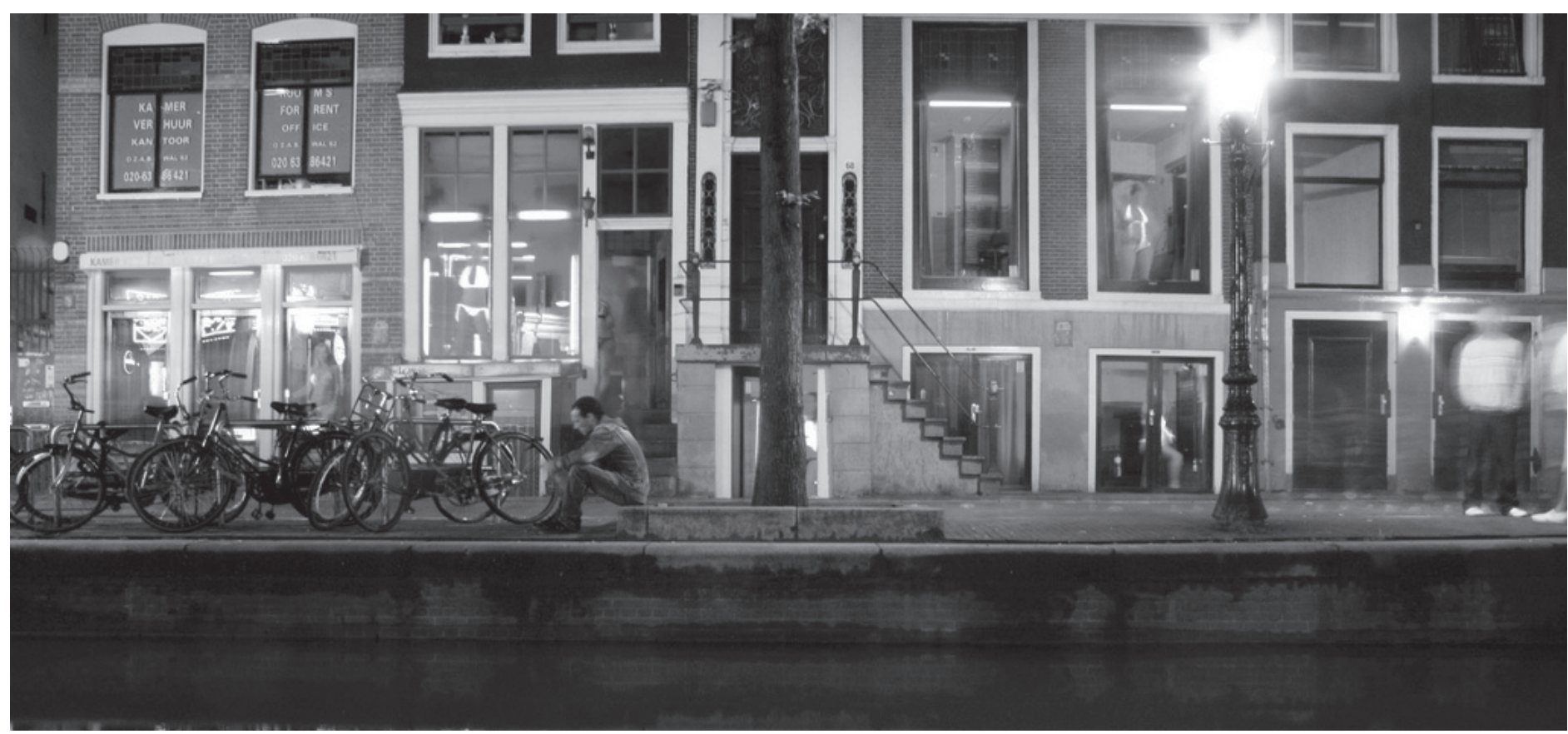

Raamprostitutie

invoering daarvan in 1911, de uitkomst van een trend. Denemarken ging Nederland bijvoorbeeld al voor in 1998. En hoewel de legalisering in Nederland soms gezien werd als typisch Paars beleid, had CDAminister Hirsh Ballin al eerder een poging daartoe gedaan. Eigenlijk waren eind twintigste eeuw alleen de kleine christelijke partijen principieel tegen legalisering. Belangrijke argumenten voor de legalisering waren het recht op vrije arbeid, maar ook dat misstanden in de prostitutiesector beter zouden kunnen worden tegengegaan. Seksueel geweld, minderjarige prostitutie en dwang werden genoemd als zorgwekkende ontwikkelingen die men na legalisering beter dacht te kunnen bestrijden. De heersende gedachte was, dat legalisering controle makkelijker zou maken en onvrijwillige prostitutie beter aangepakt zou kunnen worden. Het eerdere gedoogbeleid maakte het moeilijk onderscheid te maken tussen wat wel en niet mocht; door afschaffing van het bordeelverbod kon de sector gereguleerd worden en prostituees beter beschermd.

In 2005 kwamen twee Amsterdamse PvdA-raadsleden, Amma Asante en Karina Schaapman, met het rapport Het onzichtbare zichtbaar gemaakt. Zij beweerden dat het afschaffen van het bordeelverbod prostitutie onzichtbaarder en daarmee moeilijker controleerbaar had gemaakt: er werkten meer illegalen en minderjarigen in de sector dan voor de legalisering. In 2000 werkten in Amsterdam naar schatting acht- tot tienduizend prostituees, waarvan 30 procent achter het raam, 30 procent in besloten sekshuizen, 10 procent op straat en 30 procent ergens anders (vooral in de escortbranche en thuis). In vijf jaar tijd halveerde het aandeel van de raamprostitutie terwijl het aandeel in de besloten sekshuizen en met name in de escort- en thuiswerkbranche toenam. Asante en Schaapman stelden vast dat veel problemen vooral voorkwamen in de escortbranche. Na het afschaffen van het bordeelverbod waren vanuit de gelegaliseerde raamprostitutie illegale prostituees in deze ongereguleerde branche 'verdwenen'. De lokale politiek in Amsterdam probeert sindsdien de prostitutie weer in te dammen, maar keert zich daarbij vooral tegen het minst problematische maar meest zichtbare onderdeel van de sector: de goedgereguleerde en ruimtelijk geconcentreerde raamprostitutie.

\section{Plan 1012 en de sanering van De Wallen}

Raamprostitutie is per definitie geconcentreerd in rosse buurten, waarvan de Amsterdamse Wallen niet alleen de bekendste in Nederland, maar zelfs in de hele wereld is (ook al was de Antwerpse rosse buurt jarenlang groter in omvang). Sinds enkele jaren koopt de gemeente Amsterdam, samen met enkele woningcorporaties panden van verhuurders van rosse ramen. In het najaar van 2007 kocht NV Stadsgoed, twintig panden met circa vijftig ramen van raamexploitant Charles Geerts. Volgens velen ging het om een derde van de rosse ramen op de Wallen, maar aangezien andere tellingen het aantal ramen op de Wallen schatten op 250 tot 300, ging het wellicht om minder dan twintig procent. Daarna volgden nog een aantal kleinere opkoopacties. Bovendien zijn verschillende vergunningen van seksbedrijven ingetrokken. Tevens lanceerde de gemeente Amsterdam onder leiding van PvdA-wethouder Lodewijk Asscher in 2007 'Plan 1012', dat in 2008 verder werd uitgewerkt. Het plan is genoemd naar de postcode waarin niet alleen de Wallen liggen, maar ook een groot deel van het kernwinkelgebied van de Binnenstad, de kleinere rosse buurt tussen de Singel en de Spuistraat, en de buurt rondom Spui, Nes en Oudemanhuispoort. Het plan voorziet in een sanering van de raamprostitutie, waaronder het sluiten van driekwart van de rosse ramen op de Wallen. Ook het aantal coffeeshops en souvenirwinkels moet volgens de plannen afnemen. Er is eveneens voorzien in een 'junkvrije zone'. Een belangrijk argument voor Plan 1012 is dat deze buurt in handen is van criminogene bedrijven en moet worden teruggewonnen in het belang van de publieke zaak. Daarbij worden onder andere misstanden in de prostitutiesector aangegrepen. Asscher laat geen moment onbenut om te wijzen op de positie van vrouwen op de Wallen, maar een deel van de critici beweert dat prostituees er alleen maar op achteruit zullen gaan als Plan 1012 wordt ingevoerd. Minder raamprosti- 
tutie leidt waarschijnlijk niet tot minder prostitutie in Amsterdam, maar tot een toename van het aantal prostituees dat werkzaam is in sekshuizen, vanuit huis en in de escortbranche; deelmarkten die ruimtelijk verspreid en slechter te controleren zijn en waarvan al eerder bleek, ondermeer uit het onderzoek van Asschers partijgenoten, dat die de meeste problemen herbergen.

Het verleden lijkt te leren dat voor prostitutie geldt: hoe groter de (formele) controle, des te kleiner de controleerbaarheid. Het sluiten van ramen helpt dus niet in de bestrijding van de uitwassen van prostitutie, maar zal juist leiden tot slechter controleerbare uitwassen in andere deelmarkten. De afschaffing van het bordeelverbod in 2000 heeft niet geleid tot een betere controleerbaarheid van de prostitutiesector en Plan 1012 zal waarschijnlijk een verdere toename van de slecht controleerbare prostitutie in gang zetten ten koste van de relatief goed controleerbare raamprostitutie. Waar de legalisering een pushfactor vormde voor illegale prostituees om de relatief veilige Wallen te verlaten, lijkt Plan 1012 de rest van de raamprostituees de schimmige deelmarkten in te duwen. Hier zullen zij waarschijnlijk een grote vraag ontmoeten naar, via het internet, anonieme en 'onzichtbare' afspraakjes. Toeristen die juist voor de Wallen naar Amsterdam trekken, blijven daarentegen met lege handen staan. Voor de junkvrije zone is tot nu toe weinig aandacht geweest. Te vrezen valt dat het, net als na het schoonvegen van de Amsterdamse Zeedijk of het Rotterdamse Westersingelgebied, niet zal leiden tot een afname van het aantal junks, maar tot een verplaatsing van het centrum naar andere zwakke buurten.

\section{Formele concentratie en informele deconcentratie}

Paradoxaal genoeg heeft in het verleden zowel het legaliseren als het verbieden van prostitutie ruimtelijke deconcentratie in de hand gewerkt. Met het verbod van 1911 verdween prostitutie uit het straatbeeld en ging zij ondergronds. Daar gebeurde waarschijnlijk veel dat absoluut niet door de beugel kon, maar doordat de informele manifestaties van prostitutie minder zichtbaar waren, sloop een zekere onverschilligheid ten aanzien van prostitutie de maatschappij in. $\mathrm{Na}$ de Tweede Wereldoorlog verwaterde daarom de strenge opstelling van de overheid evenals de discussie. Zolang deze verwarring aanhield, kon prostitutie zich weer naar lieve lust concentreren in rosse buurten. Onverschilligheid, onduidelijkheid of controverse over haar status geeft prostitutie namelijk de vrijheid om, op eigen houtje en naar eigen inzicht, zich in al haar vormen te vestigen waar dat het beste uitkomt. Prostituees konden zich weer tonen en zo nam raamprostitutie een sterke vlucht.

Met de legalisering van 2000 nam raamprostitutie weer af en namen minder gereguleerde vormen van prostitutie toe. De legalisering zorgde namelijk voor een nieuwe dominante houding ten opzichte van dit fenomeen, en een poging tot beheersing. Ook al werd prostitutie deze keer juist wel toegestaan, was dat alleen binnen zeer specifieke voorwaarden het geval. In juridische zin mogen verbieden en legaliseren tegenover elkaar staan, de ruimtelijke effecten lijken opvallend veel op elkaar. Plan 1012 neemt een iets andere positie in aangezien een afname van raamprostitutie een expliciet doel is en geen neveneffect van beleid. Maar omdat het sluiten van ramen niet tot een afname van prostitutie leidt maar tot een verschuiving in het aanbod, is het neveneffect wederom ruimtelijke deconcentratie als gevolg van het steeds verder ondergronds gaan van de prostitutiesector.

Plan 1012 bestrijdt hoofdzakelijk de negatieve beeldvorming van prostitutie aangezien die vooral wordt bepaald door de zeer zichtbare rosse buurt. Deze fungeert, net als de bordelen vroeger, vooral als publiek symbool en bliksemafleider voor een omvangrijke en veelormige sector. Het beleid ten aanzien van prostitutie heeft nauwelijks invloed op het bestaan ervan, maar bepaalt wel in welke mate men ruimtelijk geconfronteerd wordt met prostitutie. De mate van ruimtelijke confrontatie heeft weer invloed op de beeldvorming en deze heeft op haar beurt weer invloed op het gevoerde beleid. De cirkel is rond. De situatie van prostituees wordt niet verbeterd met Plan 1012, maar de Wallen worden er wel mee veilig gemakkt voor investeringen. Wethouder Asscher verkoopt Plan 1012 als een pleidooi tegen criminaliteit en voor vrouwenrechten, maar het is in vele opzichten vooral een pleidooi voor het op gang houden van de groeicoalitie waarin de gemeente Amsterdam een centrale positie inneemt. Niet voor niets werkt de gemeente niet alleen samen met organisaties met een publieke taak, zoals woningcorporaties, maar ook met private partijen zoals grootwinkelbedrijven, beleggingsfondsen en hotelketens. Het aan de Dam gelegen Hotel Krasnapolsky heeft bijvoorbeeld plannen liggen om 120 miljoen euro te investeren in de buurt. Op 17 december werden Plan 1012 ook niet gepresenteerd in het Stadshuis maar in Hotel Krasnapolsky.

Het probleem is niet dat Plan 1012 criminogene sectoren wil aanpakken, het probleem is dat het vooral de ruimtelijke concentratie aanpakt van deze sectoren en niet de wortel van het probleem. Als raam- en coffeeshopexploitanten werkelijk massaal deel uit maken van de criminele sector helpt uitkopen uit postcode 1012 weinig: het verdiende geld kan immers elders worden geïnvesteerd. Wel helpt het de groeicoalitie om de intrinsieke waarde van zo'n centraal gelegen stuk van de historische stad te exploiteren.

\section{Manuel Aalbers (m.b.aalbers@uva.nl) en Michaël Deinema (m.n.deinema@uva.nl) zijn respectievelijk als postdoc en als promovendus werkzaam bij onderzoeksinstituut AMIDSt van de Universiteit van Amsterdam.}

\section{Literatuurselectie}

Aalbers, M.B. (2005) Big sister is watching you! Gender interaction and the unwritten rules of the Amsterdam red-light district. The Journal of Sex Research 42(1): 54-62.

Bossenbroek, M. \& J.H. Kompagnie (1998) Het mystery van de verdwenen bordelen. Prostitutie in Nederland in de negentiende eeuw. Amsterdam: Bert Bakker.

Deinema, M.N. (2006) Saving the involuntary sinner. The political dimensions of the sinfulness and victimization of prostitutes for the evangelical antiprostitution movement in the Netherlands, 1846-1911. Masterscriptie aan de afdeling Economische en Sociale Geschiedenis, Universiteit van Amsterdam. Mollenkopf, J. (1983) The contested city. Princeton: Princeton University Press. Wildt, A.C.C. de \& P. Arnoldussen (2002) Liefde te koop: vier eeuwen prostitutie in Amsterdam. Zes wandelingen. Amsterdam: Lubberhuizen. 